\title{
Экономические причины эйджизма на рынке труда
}

Б.Ж. ТАГАРОВ, кандидат экономических наук, Байкальский государственный университет, Иркутск. E-mail: batot@rambler.ru

Аннотация. В статье проводится анализ причин дискриминации на рынке труда по возрастному признаку. Методологической основой послужили исследования в области статистической и ценовой дискриминации. Автор выделил ключевые источники статистической дискриминации в отношении пожилых людей, показав их информационную природу. В частности, проведен анализ дискриминации, вызванной различиями в среднегрупповых показателях и разницей в разбросе показателей внутри группы, рассмотрена монопсоническая дискриминация и проанализированы факторы, влияющие на монопольную власть работодателя над работниками старшей возрастной группы. Рассмотрено влияние статистической дискриминации на монопсоническую. Показана взаимосвязь между уровнем специфичности человеческого капитала пожилого работника и степенью монопсонии работодателя. Сделан вывод об усилении статистической дискриминации пожилых работников из-за введения административных мер по борьбе с дискриминацией.

Ключевые слова: статистическая дискриминация; рынок труда; эйджизм; монопсоническая дискриминация; пенсионный возраст

\section{Введение}

Средний возраст населения растет практически во всех странах мира, что является следствием повышения качества жизни, совершенствования систем здравоохранения и образования и прочих факторов, связанных с экономическим ростом и социальным развитием. Согласно последнему изданию отчета ООН «Мировые демографические перспективы» ${ }^{1}$, на конец 2017 г. 13\% мирового населения (962 млн чел.) составляли люди в возрасте 60 лет и выше. Авторы отчета прогнозируют рост численности населения данной возрастной категории до 1,4 млрд чел. к 2030 г. Число людей старше 80 лет к 2018 г. достигло 137 млн чел., а к 2020 г. их количество вырастет до 425 млн чел.

Данная тенденция не обошла и Россию (табл. 1).

${ }^{1} \mathrm{OOH}:$ Отчет «Мировые демографические перспективы: пересмотренное издание 2017 года». URL: https://esa.un.org/unpd/wpp/Publications/Files/WPP2017_KeyFindings. pdf (дата обращения: 16.05.2019). 
Таблица 1. Возрастная структура населения России (1989-2018 гг.)

\begin{tabular}{|l|c|c|c|c|c|}
\hline \multicolumn{1}{|c|}{ Население } & $\mathbf{1 9 8 9}$ & $\mathbf{2 0 0 2}$ & $\mathbf{2 0 1 0}$ & $\mathbf{2 0 1 4}$ & $\mathbf{2 0 1 8}$ \\
\hline Всего, тыс. чел. & 147022 & 145167 & 142857 & 143667 & 146880 \\
\hline В том числе в возрасте, лет: & & & & & \\
\hline $0-24$ & 53707 & 48013 & 42227 & 40311 & 39970 \\
\hline $25-44$ & 44767 & 43211 & 42375 & 44546 & 45764 \\
\hline $45-59$ & 25947 & 27024 & 32177 & 31005 & 29920 \\
\hline 60 и более & 22516 & 26797 & 26044 & 27805 & 31226 \\
\hline $\begin{array}{l}\text { Численность населения моложе трудоспособного } \\
\text { возраста (лица в возрасте 0-15 лет), тыс. чел. }\end{array}$ & 35995 & 26327 & 23126 & 24717 & 27254 \\
\hline $\begin{array}{l}\text { Численность населения в трудоспособном возрасте } \\
\text { (мужчины в возрасте 16-59 лет, женщины - } \\
\text { 16-54 года), тыс. чел. }\end{array}$ & 83746 & 88942 & 87983 & 85162 & 82264 \\
\hline $\begin{array}{l}\text { Численность населения старше трудоспособного } \\
\text { возраста (мужчины в возрасте 60 лет и старше, } \\
\text { женщины в возрасте 55 лет и старше), тыс. чел. }\end{array}$ & 27196 & 29778 & 31714 & 33788 & 37362 \\
\hline $\begin{array}{l}\text { Доля лиц старше трудоспособного возрастав общей } \\
\text { численности населения,\% }\end{array}$ & 18 & 21 & 22 & 24 & 25 \\
\hline $\begin{array}{l}\text { Доля лиц в трудоспособном возрасте в общей } \\
\text { численности населения,\% }\end{array}$ & 57 & 61 & 62 & 59 & 56 \\
\hline Доля лиц моложе трудоспособного возраста,\% & 24 & 18 & 16 & 17 & 19 \\
\hline
\end{tabular}

Источник: составлено автором по данным Росстата. URL: http://www.gks.ru/ wps/wcm/connect/rosstat_main/rosstat/ru/statistics/population/demography/\# (дата обращения: 16.05.2019).

Как видим, доля лиц старше трудоспособного возраста в общей численности населения страны за 1989-2017 гг. выросла с 18,5\% до 25,4\%. При этом доля потенциальной рабочей силы (то есть лиц, не достигших трудоспособного возраста) сократилась с 24,5\% до 18,5\%. Такие изменения возрастной структуры вызваны снижением рождаемости в России в 1990-х гг, а также вступлением в пожилой возраст относительно многочисленных первых послевоенных поколений. Это означает, что доля пожилых людей будет расти и дальше, а доля лиц в трудоспособном возрасте продолжит сокращаться (с 2002 г. по 2017 г. она снизилась на 5 п.п.).

Указанные тенденции, а также повышение пенсионного возраста в России ${ }^{2}$ обострили проблему дискриминации на рынке труда по возрастному признаку. Необходимость совершенствования

\footnotetext{
${ }^{2}$ C 01.01.2019 г., согласно федеральному закону от 03.10.2018 № 350-Ф3 «О внесении изменений в отдельные законодательные акты Российской Федерации по вопросам назначении и выплаты пенсий» началось поэтапное повышение пенсионного возраста в России.
} 
методов борьбы с данным явлением повышает актуальность изучения его характера и причин возникновения.

Рассмотрим влияние возрастного фактора на уровень занятости и заработную плату, проанализируем экономические причины возрастной дискриминации и монопольной власти работодателя.

\section{Влияние возрастного фактора на заработную плату}

Рост среднего возраста населения вызвал изменение структуры занятости: среди работающего населения увеличилась доля пожилых граждан, в том числе преодолевших порог установленного пенсионного возраста. Это вызвано не только демографическими факторами и дефицитом «молодой» рабочей силы. Автоматизация производства, повышение доли интеллектуального труда, рост сферы услуг и прочие «постиндустриальные» тенденции, наблюдающиеся в современной экономике, увеличивают продолжительность трудовой жизни людей. С другой стороны, этому способствует повышение величины человеческого капитала возрастных работников: улучшение здоровья, повышение уровня образования и пр. Так, например, доля людей, имеющих высшее образование, среди лиц старше 55 лет в 2012 г. составила 21\%, тогда как в 1994 г. - всего 11\%, а доля людей, оценивающих свое состояние здоровья как плохое, с 1994 г. по 2012 г. сократилась с 40\% до 30\% [Колосницына, Герасимова, 2014].

Данные об изменении доли пожилых людей в работающем населении в течение 2011-2017 гг. представлены в таблице 2.

Таблица 2. Доля пожилых людей в общем числе занятых (2011-2017 гг.),\%

\begin{tabular}{|l|c|c|c|c|}
\hline \multirow{2}{*}{ Год } & \multicolumn{2}{|c|}{ От $\mathbf{5 5}$ до 59 лет } & \multicolumn{2}{c|}{ От 60-72 лет } \\
\cline { 2 - 5 } & мужчины & женщины & мужчины & женщины \\
\hline 2011 & 8,8 & 8,2 & 4,5 & 4,6 \\
\hline 2013 & 9 & 8,6 & 4,6 & 4,8 \\
\hline 2015 & 9,5 & 9 & 4,9 & 5,3 \\
\hline 2017 & 10 & 9,2 & 5,2 & 5,5 \\
\hline
\end{tabular}

Источник табл. 2, 3: составлено автором по данным Росстата. URL: http://www. gks.ru/wps/wcm/connect/rosstat_main/rosstat/ru/statistics/population/generation/\# (дата обращения: 16.05.2019).

Как видим, доля работников старше 55 лет в структуре занятости растет. Но оценка уровня занятости в соответствующей 
возрастной группе (табл. 3) показывает, что трудовая активность пожилых за эти годы на самом деле не выросла.

Таблица 3. Уровень занятости населения в возрасте 55-72 лет, \% от численности населения соответствующей возрастной группы

\begin{tabular}{|l|c|c|c|c|c|c|}
\hline \multirow{2}{*}{ Год } & \multicolumn{2}{|c|}{ От 55 до 59 лет } & \multicolumn{2}{|c|}{ От 60-72 лет } & \multicolumn{2}{c|}{$\begin{array}{c}\text { Уровень занятости } \\
\text { в целом }\end{array}$} \\
\cline { 2 - 7 } & мужчины & женщины & мужчины & женщины & мужчины & женщины \\
\hline 2011 & 72,7 & 49,9 & 26,3 & 16,3 & 69,2 & 59,2 \\
\hline 2013 & 73,9 & 52 & 27 & 17,1 & 70,4 & 59,8 \\
\hline 2015 & 74,6 & 52,3 & 27,6 & 18,5 & 71,1 & 60,1 \\
\hline 2017 & 75,5 & 52 & 26,5 & 17,3 & 71,5 & 60,1 \\
\hline
\end{tabular}

Из-за того, что количество пожилых людей растет несколько быстрее, чем их занятость, доля занятых среди лиц пенсионного возраста снижается - как у мужчин, так и у женщин.

По данным Росстата, уровень занятости среди населения старше трудоспоспособного возраста снизился с 30,1\% в 2015 г. до $28,8 \%$ в 2017-м. При этом уровень безработицы ${ }^{3}$ в этой же возрастной группе увеличился с $3 \%$ до 3,3\%. Причин у этого феномена может быть много, но, несомненно, свою лепту вносит и дискриминация на рынке труда по возрастному признаку, или геронтологический эйджизм ${ }^{4}$.

Существует множество аспектов трудовой деятельности, в которых может проявиться гендерная или возрастная дискриминация: условия труда, продвижение по карьерной лестнице, принятие решения при найме и пр., но наиболее явный из них - дифференциация заработной платы, что отчетливо видно по данным таблицы 4.

Из данных таблицы видно, что отношение заработной платы пожилых к средней по экономике уменьшается с 2015 г. Согласно классификации Е.А. Трофимова [Трофимов, Трофимова, 2018], средняя заработная плата работников старше 65 лет приближает их к критической зоне рынка труда ${ }^{5}$.

\footnotetext{
${ }^{3}$ Безработными граждане пенсионного возраста признаются в том случае, если они занимаются поиском работы и готовы приступить к ней.

${ }^{4}$ В 1969 г. американский социолог Р. Батлер предложил для обозначения возрастной дискриминации использовать понятие эйджизм [Butler, 1969].

${ }^{5}$ Из работы Е.А. Трофимова: «Критическая зона рынка труда охватывает ту часть населения, которая находится в сложном материальном положении из-за ... частичного отсутствия работы или низкого уровня ее оплаты».
} 


\section{Таблица 4. Номинальная начисленная заработная плата в России в 2011-2017 rr., руб.}

\begin{tabular}{|c|c|c|c|c|c|c|c|c|}
\hline \multirow[t]{2}{*}{ Год } & \multicolumn{2}{|c|}{ От 55 до 59 лет } & \multicolumn{2}{|c|}{ От 60 до 64 лет } & \multicolumn{2}{|c|}{ От 65 и старше } & \multicolumn{2}{|c|}{$\begin{array}{l}\text { Средняя заработ- } \\
\text { ная плата в эко- } \\
\text { номике в целом }\end{array}$} \\
\hline & муж. & жен. & муж. & жен. & муж. & жен. & муж. & жен. \\
\hline 2011 & 25312 & 17727 & 23722 & 16916 & 23632 & 16609 & 30005 & 19219 \\
\hline 2013 & 29746 & 23238 & 28532 & 21906 & 29366 & 21712 & 33301 & 24721 \\
\hline 2015 & 33773 & 26273 & 32269 & 24864 & 33891 & 26255 & 38605 & 28021 \\
\hline 2017 & 38622 & 30465 & 36304 & 28269 & 37102 & 28148 & 45557 & 32658 \\
\hline \multicolumn{9}{|c|}{$\begin{array}{c}\text { Отношение средней заработной платы в возрастной группе } \\
\text { к средней заработной плате по экономике,\% }\end{array}$} \\
\hline 2011 & 84 & 92 & 79 & 88 & 79 & 86 & 100 & 100 \\
\hline 2013 & 89 & 94 & 86 & 89 & 88 & 88 & 100 & 100 \\
\hline 2015 & 87 & 94 & 84 & 89 & 88 & 94 & 100 & 100 \\
\hline 2017 & 84 & 93 & 80 & 86 & 81 & 8 & 100 & 100 \\
\hline
\end{tabular}

Источник: составлено автором по данным Росстата. URL: http://www.gks.ru/ wps/wcm/connect/rosstat_main/rosstat/ru/statistics/wages/ (дата обращения: 16.05.2019).

Такое относительное снижение зарплаты пожилых работников можно было бы связать с ухудшением ситуации на рынке труда из-за кризиса 2014 г., но, как свидетельствуют данные таблицы 3, уровень занятости в экономике все эти годы только рос, так что скорее всего мы имеем здесь дело с проявлением дискриминации.

Е.А. Клепикова и М.Г. Колосницына, проанализировав данные Российского мониторинга экономического положения и здоровья населения НИУ ВШЭ чия в средней заработной плате разных возрастных групп на те, что вызваны дискриминацией, и те, в основе которых лежит объективная разница в производительности труда [Клепикова, Колосницына, 2017]. Их исследование показало, что «вклад» дискриминации в снижение среднего заработка в возрастной группе 55-64 года относительно зарплаты у 45-54-летних составляет $22 \%$ у мужчин и $16 \%$ у женщин. В данной работе также отмечается, что в России максимальный уровень зарплаты приходится на возрастную группу 25-44 года, тогда как в развитых

${ }^{6}$ Российский мониторинг экономического положения и здоровья населения НИУ ВШЭ (RLMS HSE), проводимый Национальным исследовательским университетом «Высшая школа экономики» и ЗАО «Демоскоп» при участии Центра народонаселения Университета Северной Каролины (Чапел-Хилл, США) и Института социологии РАН. URL: http://www.hse.ru/rlms (дата обращения: 16.05.2019). 
странах - на специалистов в возрасте 45-59 лет. И хотя этот разрыв может быть объяснен объективными факторами, такими как структура экономики, средняя продолжительность жизни и качество системы здравоохранения, уровень автоматизации производства и разделения труда в фирмах [Анохов, 2016], вклад в него дискриминации тоже довольно значителен.

\section{Экономические причины эйджизма на рынке труда}

Работодатель может отказываться от найма пожилых работников не только по экономическим причинам, но и из-за личных психологических проблем (например, геронтофобии ${ }^{7}$ ), или же социально-обусловленной неприязни. Такого рода дискриминация на рынке труда была подробно исследована Г. Беккером, который показал, что она приводит к потерям не только у дискриминируемой социальной группы, но и у работодателя [Becker, 1957]. Действительно, последний, ущемляя пожилых соискателей, вне связи с их трудовыми навыками и качеством работы, платит повышенную заработную плату более молодым работникам, не получая от этого реальной отдачи. Если рынок, на котором действует его фирма, является конкурентным, подобное поведение может привести к потере ее конкурентоспособности. Причиной этого, согласно Беккеру, будет появление компаний, готовых принять на работу более опытных, но дискриминируемых по неэкономическим признакам работников, готовых работать за меньшее вознаграждение.

Впрочем, в наши дни подобного рода эйджизм, основанный на предрассудках, играет все меньшую роль. Поэтому в данной работе мы уделим внимание экономическим причинам дискриминации, связанным с желанием работодателя максимизировать отдачу от использования рабочей силы. К ним можно отнести негативные стереотипы, статистическую и монопсоническую дискриминацию.

\section{Негативные стереотипы восприятия пожильх людей}

Под стереотипом восприятия в контексте данной работы понимается устоявшееся в обществе мнение относительно

\footnotetext{
${ }^{7}$ В медицине данный термин обозначает разновидность психических заболеваний, выражающихся в страхе или ненависти перед контактами с пожилыми людьми и/или собственным старением.
} 
определенных профессиональных качеств работника, влияющих на его эффективность.

Многочисленные зарубежные и отечественные исследования показали, что в обществе сложились стереотипы относительно пожилых людей, которые негативно влияют на оценку их профессионализма и деловых качеств и могут оказать решающее воздействие на решение работодателя о найме и определении условий труда для возрастных соискателей. Причем, очень часто люди сами не осознают этой предубежденности. Например, Дж. Арбакл и Б. Вильямс провели эксперимент, попросив студентов оценить качество лекции, показанной им с использованием слайдов [Arbuckle, Williams, 2003]. Притом, что в обоих случаях текст был один и тот же, если на фото был изображен молодой преподаватель, студенты давали более высокую оценку, чем в случае, когда на слайдах фигурировал портрет пожилого человека.

Многочисленные опросы показывают, что пожилые люди в целом ассоциируются у общества со слабой тягой и низкими возможностями к познанию нового, склонностью к духовным, а не материальным ценностям, негибкостью, нежеланием выходить из зоны комфорта и пр. [Лемиш, 2015]. В России на вопрос ВЦИОМ «Какие чувства Вы обычно испытываете, когда видите пожилого человека?» $38 \%$ респондентов ответили - жалость [Хоткина, 2013].

При этом не все негативные стереотипы связаны с трудовыми навыками пожилых работников. Многие руководители считают, что большая разница в возрасте может стать источником дискомфорта и разлада в коллективе, особенно при работе в совместных проектах [Thatcher, Patel, 2011].

Существующие стереотипы относительно пожилых людей породили другой стереотип - неформальную классификацию рабочих мест по критерию возраста работников, подходящих для них наилучшим образом [Gordon, Arvey, 1986]. Например, часть работодателей полагают, что для пожилых людей подходят в первую очередь руководящие должности, тогда как их нахождение на рядовых позициях неизбежно приведет к конфликтам с более молодым начальником.

Заметим, что ряд исследований показали несправедливость многих подобных предубеждений. Например, Р. Постума и М. Кампион [Posthuma, Campion, 2009] пришли к выводу, что такие стереотипы, 
как снижение производительности труда или неспособность к восприятию новых знаний у пожилых работников, в подавляющем большинстве случаев не соответствуют действительности. А С. Биггс с коллегами развенчали миф о негативном влиянии уровня здоровья на качество работы пожилых людей [Biggs et al., 2012].

\section{Статистическая дискриминаџия}

Негативные стереотипы восприятия пожилых людей, основанные на предубеждениях, дополненные неверной интерпретацией статистических данных, порождают статистическую дискриминацию, опирающуюся на якобы объективную информацию о средней производительности труда в разных возрастных группах. Подробный анализ статистической дискриминации был впервые проведен Е. Фелпсом, который рассмотрел ее расовую и гендерную разновидности [Phelps, 1972]. Мы постараемся применить анализ Фелпса к проблеме эйджизма.

В первой ситуации имеются две социальные группы с разной средней производительностью труда. Работодатель имеет статистические данные о среднем качестве работников в каждой из групп, но не может оценить производительность каждого конкретного работника без дополнительных затрат. Нежелание нести эти дополнительные издержки побуждает его принимать решения о найме и вознаграждении работников исходя из усредненных групповых характеристик. Такой подход поставит любого представителя более производительной группы в лучшее положение относительно его коллег из другой группы вне зависимости от реальных трудовых навыков.

По аналогии, работодатель, имея негативные данные относительно пожилых людей как работников в целом, будет дискриминировать конкретного пожилого работника, если при их взаимодействии будет иметь место асимметрия информации, а издержки на ее преодоление будут сравнительно велики. Однако если производительность труда конкретного работника данной возрастной группы будет полностью видна работодателю, статистическая дискриминация не возникнет.

Приведем конкретные наглядные примеры. В основе статистической дискриминации пожилого работника может лежать, к примеру, высокий уровень асимметрии информации относительно его планов по саморазвитию. Как бы ни было велико пкальное 
желание работника учиться, на этапе собеседования проверить это практически невозможно, а стереотипы утверждают, что мотивация к получению новых знаний у пожилых людей в среднем ниже. Поэтому в большинстве случаев работодатель, руководствуясь общепринятой точкой зрения, будет дискриминировать работника. В противоположность этому уровень владения информационными технологиями, как легкопроверяемый признак, как правило, не является основой для статистической дискриминации.

Бывает и так, что среднее качество работников в обеих группах имеет одинаковый уровень, но стоимость получения информации о реальной производительности труда каждого конкретного работника из первой группы ниже, чем из второй. В такой ситуации представитель первой группы получит преимущество, так как его наем будет связан с меньшими затратами.

Применительно к дискриминации по возрасту это означает, что работодатель предпочтет того соискателя, о трудовых навыках и производительности которого ему будет дешевле (проще) получить информацию. Здесь ситуация может быть двоякой. С одной стороны, квалифицированные пожилые работники, имеющие солидный профессиональный опыт, могут предоставить о себе больше информации, чем их менее опытные коллеги, и получить преимущество при трудоустройстве. С другой стороны, качество информационного сигнала, исходящего от молодых, может оказаться более высоким (например, в их дипломе почти наверняка будет указана более актуальная специальность, чем у возрастных работников, получивших образование раньше).

Статистическая дискриминация пожилых людей может быть связана также с представлением работодателя о разбросе производительности труда в разных возрастных группах. Некоторые исследования [Dickinson, Oaxaca, 2009] показывают, что при равной средней производительности труда, работодатель, несклонный к риску, обычно предпочтет нанять представителя социальной группы с меньшей дисперсией по данному показателю.

Дискриминация, основанная на среднегрупповых признаках, в определенных условиях может привести к «порочному кругу», демотивируя представителей ущемленных групп к саморазвитию. К. Эрроу, один из основоположников данной теории, рассмотрев последствия дискриминации ряда социальных групп, показал, что у их представителей уменьшается стремление к улучшению 
трудовых навыков, поскольку затраты на повышение производительности труда не приносят соответствующей отдачи [Arrow, 1973]. Особенно плохо обстоят дела, если сами работники не в состоянии изменить признак, на основе которого проводится дискриминация. Нежелание таких людей инвестировать в собственный человеческий капитал снижает среднегрупповые показатели и еще больше подрывает шансы на исправление ситуации. В результате предубежденность работодателей к представителям данной группы оказывается «оправданной», дискриминация усиливается, мотивация к развитию снижается еще больше. Этот феномен Эрроу назвал «самосбывающимся пророчеством».

Его теория применима и к объяснению некоторых аспектов эйджизма. Пожилые люди, сталкиваясь с дискриминацией на рынке труда и не получая отдачи от поисков и выполнения работы, теряют мотивацию к совершенствованию своих трудовых качеств и больше внимания начинают уделять семье, отдыху, заботе о здоровье, духовным ценностям и т.П. [Крутикова, 2016]. Теория Эрроу говорит о том, что такая смена жизненных приоритетов во многом порождена снижением доходности трудового капитала пожилых. Это, в свою очередь, вызывает усиление негативных стереотипов у работодателей и у самих людей пенсионного и предпенсионного возраста, демотивируя их к продолжению карьеры.

Сомнения относительно собственной ценности и ущемление со стороны работодателей приводят к неуверенности пожилых работников в своем будущем. Так, согласно опросу, проведенному ВНИИ труда Минтруда России [Забелина, 2018], 46\% занятых старше 50 лет считают, что не смогут найти другую работу в случае увольнения, 32\% опрошенных полагают, что найдут новое рабочее место, но с большим трудом. Вкупе с занижением самооценки и низкими зарплатными ожиданиями подобный пессимизм заставляет людей пенсионного и предпенсионного возраста соглашаться на дискриминационные условия, что лишь убеждает работодателей в правильности собственной позиции и затрудняет выход из «порочного круга».

\section{Монопсоническая дискриминация}

Теория ценовой дискриминации была разработана Ж. Дюпюи [Дюпюи, 1993] и Д. Ларднером (цит. по [Hooks, 1971]), положившими в ее основу идею о различии полезности товара для разных 
покупателей и постулат о стремлении монополий к максимизации прибыли. В свою очередь А. Пигу [Пигу, 1985], развив эту теорию, определил условия, при которых ценовая дискриминация возможна, и выделил ее основные виды.

На рынке труда ценовая дискриминация проявляется в форме монопсонической дискриминации. Работодатель, обладающий монопольной властью над работниками, может дифференцировать заработную плату и условия труда в зависимости от степени эластичности их предложения. Относительная неэластичность предложения пожилых работников может быть вызвана следующими факторами.

1. Низкая вероятность найти другую работу с таким же уровнем заработной платы из-за статистической дискриминации.

Причины возникновения этой проблемы были исследованы Б. Гринвальдом [Greenwald, 1986]. В отношении пожилых работников с большим стажем работы она проявляется особенно остро. Информация о производительности труда работника, достаточно долго проработавшего в компании, как правило, не составляет секрета для его нынешнего работодателя. В случае, если качество такого работника выше среднего по его социальной группе, работодатель обычно проявляет готовность выплачивать ему повышенное вознаграждение, но... не достигающее уровня его предельного продукта. При этом другие работодатели, не знающие о реальных достоинствах работника, скорее всего, будут оценивать его по среднестатистическим показателям дискриминируемой группы и предложат ему соответствующую заработную плату. Таким образом, работник оказывается привязан к существующему рабочему месту, ведь в случае смены работы его неизбежно ждет резкое снижение заработной платы.

2. Меньшая информированность о ситуации на рынке труда по сравнению с более молодыми работниками.

Это может быть связано с двумя причинами. Во-первых, с увеличением возраста, как было отмечено, снижается мотивация к смене места работы, а вместе с ней - и к постоянному мониторингу рынка труда. К тому же долгое нахождение в одной организации приводит к потере навыков поиска работы. Во-вторых, между представителями разных возрастных групп имеет место информационное неравенство с точки зрения использования современных информационно-коммуникационных технологий, 
которые становятся все более важным инструментом поиска вакансий и взаимодействия с потенциальным работодателем. Например, на начало 2018 г. среди жителей России 16-29 лет 98\% были пользователями Интернета. Среди лиц в возрасте 30-54 года таковых было 82\%, а старше 55 лет - лишь 36\% Что касается доступа к Интернету с помощью смартфонов, разрыв между указанными возрастными группами еще более заметен: 83\%, 58\% и 14\% соответственно. Все это усиливает монопольную власть работодателя над пожилыми работниками, поскольку высокие затраты на поиск новой работы привязывают их к существующему рабочему месту.

3. Накопленный специфический социальный и человеческий капитал.

Чем солиднее трудовой стаж работника в конкретной организации, тем больше специфических профессиональных навыков он приобретает, что повышает его ценность для данной компании по сравнению с другими, где ему пришлось бы начинать «с нуля» ${ }^{9}$ К К тому же за время работы сотрудник накапливает и позитивный социальный капитал - хорошие отношения с членами коллектива, деловую репутацию и другие социальные активы, делающие его трудовую жизнь более комфортной. Данные ресурсы создают барьеры для смены рабочего места, особенно высокие для пожилых работников, которые, ко всему прочему, не склонны менять коллектив и по психологическим причинам.

4. Наличие альтернативных источников дохода и относительно низкие расходы.

Трудовая пенсия по старости и помощь со стороны семьи дают возможность работникам пенсионного возраста покинуть работу в случае, если условия труда их не устраивают. Кроме того, в большинстве случаев пожилые люди имеют меныше постоянных расходов, чем их молодые коллеги: кредиты в основном выплачены ${ }^{10}$,

\footnotetext{
${ }^{8}$ Исследование GfK: Проникновение Интернета в России. URL: http://www.gfk.com/ ru/insaity/press-release/issledovanie-gfk-proniknovenie-interneta-v-rossii/ (дата обращения: 16.05.2019).

9 Подробный анализ специфического человеческого капитала и специфических ресурсов был проведен Г. Беккером [Becker, 1962] и О. Уильямсоном [Уильямсон, 1996].

${ }^{10}$ Например, по данным Национального бюро кредитных историй, средний размер ипотечного кредита в России в 1 квартале 2018 г. у лиц в возрасте 40-49 лет составлял 2,12 млн руб., а у людей в возрасте 60-65 лет-1,18 млн руб. URL: https://www.nbki.ru/ press/pressrelease/?id=21715 (дата обращения: 16.05.2019).
} 
дети встали на ноги, появились права на разного рода льготы и субсидии. С одной стороны, все это снижает возможность работодателя дискриминировать пожилых работников, так как сокращается их зависимость от трудового дохода ${ }^{11}$, но с другой - влияет и на цену предложения труда. Для лиц пенсионного возраста увеличивается нематериальная значимость работы, а размер заработной платы отходит на второй план. Работодатель, понимая это, получает стимул занижать зарплату работающим пенсионерам, ведь они все равно не уволятся.

Все указанные факторы монопсонической дискриминации связаны с более низкой мобильностью пожилых работников по сравнению с молодыми. И хотя в целом на трудовую мобильность, как указывает В.Г. Былков, влияет довольно много случайных факторов [Былков, Самарина, 2018], возрастной критерий является здесь объективной причиной. Отметим, что снижение трудовой мобильности и, как следствие, увеличение дискриминации, касается в первую очередь пожилых работников с относительно высокой производительностью труда и высоким уровнем социального и человеческого капитала.

\section{Выводы}

Актуальность проблемы дискриминации по возрастному признаку побуждает принимать специальные меры по борьбе с ней как отдельные государства, так и международные организации. В рекомендации МОТ от 1980 г. № 162 указано, что пожилые работники должны иметь равенство возможностей и обращения относительно всех других трудящихся, с учетом их индивидуальных способностей, опыта и квалификации. Протокол № 1 Европейской социальной хартии предписывает государствам принятие мер по обеспечению возможности пожилым людям вести независимое существование и оставаться полноценными членами общества. В России запрет на дискриминацию закреплен в статье 3 Трудового кодекса РФ. В Кодекс об административных правонарушениях несколько лет назад введена статья 13.11.1, запрещающая «распространение информации о вакантных рабочих местах (должностях), содержащей

\footnotetext{
${ }^{11}$ Согласно В.Г. Былкову [Былков, 2017], это усиливает эффект дохода, что приводит к снижению индивидуального предложения труда
} 
ограничения дискриминационного характера». В ноябре 2018 г. был принят федеральный закон № 352-Ф3, который добавил в Уголовный кодекс РФ статью 144.1, предусматривающую ответственность за необоснованный отказ в приеме на работу или необоснованное увольнение лиц, достигших предпенсионного возраста.

С точки зрения рассматриваемых в данной работе причин дискриминации по возрасту в сфере трудовых отношений, эти меры, ограничивающие работодателя в принятии решений относительно пожилых работников, влияют на эйджизм неоднозначно. Монопсоническая дискриминация снижается вслед за уменьшением возможностей для работодателя по дифференциации заработной платы и условий труда. Не случайно в бюджетных учреждениях, например, в вузах, где большую роль играют формальные признаки, дискриминации пожилых людей практически не наблюдается [Озерникова, 2018]. Статистическая дискриминация, напротив, увеличивается, потому что действия государства, повышающие потенциальные издержки работодателя, связанные с наймом пожилых работников, еще больше снижают для него и без того невысокую привлекательность данной социальной группы.

\section{Литература}

Анохов И. В. Разделение труда и эволюция фирмы // Вестник УрФУ. Серия экономика и управление. 2016. Т. 15. № 1. С. 135-151.

Былков В.Г. Предложение на рынке труда: методология, природа формирования // Baikal Research Journal. 2017. Т. 8. № 4. doi: 10.17150/24116262.2017.8(4).1. [Эл. ресурс]. URL: http://brj-bguep.ru/reader/article. aspx?id=21889 (дата обращения: 16.05.2019).

Былков В.Г., Самарина М.В. Видовые и качественные изменения спроса на рабочую силу под воздействием трудовой мобильности // Труд и социальные отношения. 2018. № 3. С. 27-38. doi: 10.20410/2073-7815-2018-29-3-27-38.

Дюпюи Ж. О мере полезности гражданских сооружений // Вехи экономической мысли. 2000. Т. 1. С. 28-66.

Забелина О.В. Особенности занятости и проблемы трудоустройства лиц старших возрастных групп на российском рынке труда // Экономика труда. 2018. T. 5, № 1. C. 165-176. doi: 10.18334/et.5.1.38874.

Клепикова Е.А., Колосницыны М.Г. Эйджизм на российском рынке труда: дискриминация в заработной плате // Российский журнал менеджмента. 2017. T. 15 , № 1. С. 69-88.

Колосницына М.Г., Герасименко М. А. Экономическая активность в пожилом возрасте и политика государства // Вопросы государственного и муниципального управления. 2014. № 4. С. 47-68. 
Крутикова В.В. Трудовой ресурс пожилых людей в России // Социальноэкономические явления и процессы. 2016. Т. 11, № 3. С. 77-82.

Лемиш В.В. Образ пожилого и старого человека в представлениях взрослых 20-39 лет // Известия Алтайского государственного университета. 2015. Т. 1, № 3-1(87). C. 64-69.

Озерникова Т.Г. Кадровые риски российских университетов // Труд и социальные отношения. 2018. № 3. С. 81-92. doi: 10.20410/2073-7815-2018-293-81-92.

Пигу А. Экономическая теория благосостояния. М.: Прогресс, 1985.

Трофимов Е.А., Трофимова Т.И. К вопросу о дискриминации на российском рынке труда // Известия Байкальского государственного университета. 2018. Т. 28, № 3. С. 419-425. doi: 10.17150/2500-2759.2018.28(3).419-425

Уильямсон О. Экономические институты капитализма. СПб.: Лениздат; CEV Press. 1996.

Хоткина 3. А. «Нормальный трудовой потенциал» и дискриминация по возрасту // Народонаселение. 2013. № 3. С. 27-37.

Arbuckle J., Williams B.D. Students' perceptions of expressiveness: age and gender effects on teacher evaluations // Sex Roles. 2003. Vol. 49, № 9/10. Pp. 507-517.

Arrow K.J. The Theory of Discrimination. In: Ashenfelter, O., Rees, A. (eds.). Discrimination in Labor Markets. Princeton University Press. 1973. Pp. 3-33.

Becker G.S. The Economics of Discrimination. Chicago: Chicago University Press. 1957.

Becker G. S. Investment in Human Capital: A Theoretical Analysis // Journal of Political Economy. 1962. Vol. 70, № 5. Pp. 9-49.

Biggs S., Carstensen L., Hogan P. Social capital, lifelong learning and social innovation. In: Beard J.L., Biggs S., Bloom D. E., Fried L.P., Kalache A., Olshansky S. J. (eds).Global Population Ageing: Peril or Promise? World Economic Forum: Geneva. 2012. Pp. 39-41.

Butler R.N. Ageism: Another form of bigotry // The Gerontologist. Vol. 9, 1969. Pp. 243-246.

Dickinson D., Oaxaca R. Statistical Discrimination in Labor Markets: An Experimental Analysis // Southern Economic Journal. 2009. Vol. 76, № 1. Pp. 16-31.

Gordon R.A, Arvey R.D. Perceived and actual ages of workers // Journal of Vocational Behavior. 1986. № 28. Pp. 21-28.

Greenwald B.C. Adverse selection in the labor market // Review of Economic Studies. 1986. Vol. 53, № 3. Pp. 325-347.

Hooks D. Monopoly Price Discrimination in 1850: Dionysius Lardner// History of Political Economy.1971. Vol. 3, № 1. Pp. 208-223.

Phelps E.S. The Statistical Theory of Racism and Sexism // The American Economic Review. 1972. Vol. 62, № 4. Pp. 659-661.

Posthuma R.A., Campion M.A. Age stereotypes in the workplace: Common stereotypes, moderators, and future research directions // Journal of Management. 2009. № 35. Pp. 158-188.

Thatcher S.M.B., Patel P.C. Demographic faultlines: a meta-analysis of the literature // Journal of Applied Psychology. 2011. № 96. Pp. 1119-1139. 
Для цитирования: Тагаров Б.Ж. Экономические принципы эйджизма на рынке труда// ЭКО. 2019. № 8. C. 66-82. DOI: 10.30680/ECO0131-7652-20198-66-82.

\section{Summary}

Tagarov, B. Zh., Cand. Sci. (Econ.), Baikal State University, Irkutsk Economic Causes of Ageism in the Labour Market

Abstract. The article analyzes the causes of discrimination in the labor market on the basis of age. The methodological basis of the article is research in the field of statistical discrimination and price discrimination. The author iden-tified the main sources of statistical discrimination against older people, show-ing their informational nature. In particular, the analysis of discrimination caused by differences in the average group indicators and discrimination relates to differences in the spread of indicators within the group. The paper considers monopsonic discrimination and analyzes factors affecting the monopoly power of the employer over employees of the older age group. The influence of statisti-cal discrimination on monopsonic discrimination is considered. The relationship between the level of specificity of the human capital of an elderly employee and the level of monopoly power of the employer is shown. It is concluded that dis-crimination against older workers is statistically increasing due to introduction of administrative measures to combat discrimination.

Keywords: statistical discrimination; labor market; ageism; monopsonic discrimination; retirement age

\section{References}

Anohov, I.V. (2016). Division of labor and evolution of the company. Vestnik UrFU. Seriya ehkonomika $i$ upravlenie. Bulletin of UrFU. Economics and management. Vol. 15. No. 1. Pp. 135-151. (In Russ.).

Arbuckle, J., Williams, B.D. (2003). Students' perceptions of expressiveness: age and gender effects on teacher evaluations. Sex Roles. Vol. 49. No. 9/10. Pp. 507-517.

Arrow, K.J. (1973). The Theory of Discrimination. In: Ashenfelter, O., Rees, A. (eds.). Discrimination in Labor Markets. Princeton University Press. Pp. 3-33.

Becker, G.S. (1957). The Economics of Discrimination. Chicago: Chicago University Press.

Becker, G.S. (1962). Investment in Human Capital: A Theoretical Analysis. Journal of Political Economy, Vol. 70. No. 5. Pp. 9-49.

Biggs, S., Carstensen, L., Hogan, P. (2012). Social capital, lifelong learning and social innovation. In: Beard J.L., Biggs S., Bloom D.E., Fried L.P., Kalache A., Olshansky S. J. (eds).Global Population Ageing: Peril or Promise? World Economic Forum: Geneva. Pp. 39-41.

Butler, R.N. (1969). Ageism: Another form of bigotry. The Gerontologist, Vol. 9. Pp. 243-246.

Bylkov, V.G. (2017). Offer on the labour market: methodology, the nature of formation. Baikal Research Journal. Baikal Research Journal. Vol. 8. No. 4. doi: 10.17150/2411-6262.2017.8(4).1. (In Russ.).

Bylkov, V.G., Samarina, M.V. (2018). Specific and qualitative changes in the demand for labour under the influence of labour mobility. Trud $i$ socialnye otnosheniya. Labour and social relations. No. 3. Pp. 27-38. doi: 10.20410/2073-7815-2018-293-27-38. (In Russ.). 
Dickinson, D., Oaxaca, R. (2009). Statistical Discrimination in Labor Markets: An Experimental Analysis. Southern Economic Journal, Vol. 76. No. 1. Pp. 16-31.

Dupuit, J. (2000). On the measure of the usefulness of civil structures. Vekhi ehkonomicheskoj mysli. Milestones of economic thought. Vol. 1. Pp. 28-66. (In Russ.).

Gordon, R.A, Arvey, R.D. (1986). Perceived and actual ages of workers. Journal of Vocational Behavior. No. 28. Pp. 21-28.

Greenwald, B.C. (1986). Adverse selection in the labor market. Review of Economic Studies, Vol. 53. No. 3. Pp. 325-347.

Hooks, D. (1971). Monopoly Price Discrimination in 1850: Dionysius Lardner. History of Political Economy, Vol. 3, No.1. Pp. 208-223.

Hotkina, Z.A. (2013). "Normal work potential" and age discrimination. Narodonaselenie. Population. No. 3. Pp. 27-37. (In Russ.).

Klepikova, E.A., Kolosnicyna, M.G. (2017). Ageism in the Russian labour market: wage discrimination. Rossijskij zhurnal menedzhmenta. Russian management journal. Vol. 15. No. 1. Pp. 69-88. (In Russ.).

Kolosnicyna, M.G., Gerasimenko, M.A. (2014). Economic activity in old age and state policy. Voprosy gosudarstvennogo i municipalnogo upravleniya. Issues of state and municipal management. No. 4. Pp. 47-68. (In Russ.).

Krutikova, V.V. (2016). Labor resource of elderly people in Russia. Socialnoehkonomicheskie yavleniya i processi. Social economic phenomena and processes. Vol. 11. No. 3. Pp. 77-82. (In Russ.).

Lemish, V.V. (2015). The image of the elderly and the old man in the views of adults 20-39 years. Izvestiya Altajskogo gosudarstvennogo universiteta. Bulletin of Altai state University. Vol. 1. No. 3-1(87). Pp. 64-69. (In Russ.).

Ozernikova, T.G. (2018). Personnel risks of Russian universities. Trud i socialnye otnosheniya. Labour and social relations. No. 3. Pp. 81-92. doi: 10.20410/20737815-2018-29-3-81-92. (In Russ.).

Phelps, E.S. (1972). The Statistical Theory of Racism and Sexism. The American Economic Review. Vol. 62. No. 4. Pp. 659-661.

Pigou, A. (1985). The Economics of Welfare. Moscow. Progress Publ. (In Russ.).

Posthuma, R.A., Campion, M.A. (2009). Age stereotypes in the workplace: Common stereotypes, moderators, and future research directions. Journal of Management. No. 35. Pp. 158-188.

Thatcher, S.M.B., Patel, P.C. (2011). Demographic faultlines: a meta-analysis of the literature. Journal of Applied Psychology. No. 96. Pp. 1119-1139.

Trofimov, E.A. Trofimova, T.I. (2018). To a question of discrimination in the Russian labor market. Izvestiya Bajkalskogo gosudarstvennogo universiteta. Bulletin of Baikal State University. Vol. 28, No. 3. Pp. 419-425. (In Russ.). doi: 10.17150/2500-2759.2018.28(3).419-425.

Williamson, O. (1996). Ekonomicheskij instituty kapitalizma. The Economic Institutions of Capitalism. SPb. Lenizdat Publ. CEV Press. (In Russ.).

Zabelina, O.V. (2018). Features of employment and problems of employment of persons of older age groups in the Russian labor market. Ekonomika truda. Labour economics. Vol. 5, No. 1. Pp. 165-176. doi: 10.18334/et.5.1.38874. (In Russ.).

For citation: Tagarov, B. Zh. (2019). Economic Causes of Ageism in the Labour Market. ECO. No. 8. Pp. 66-82. (In Russ.). DOI: 10.30680/ECO0131-7652-20198-66-82. 